\title{
THE EFFECT OF REPEATED FOUR MONTHLY TREATMENTS ON THE PREVALENCE AND WORM BURDEN OF ASCARIS, TRICHURIS AND HOOKWORM INFECTIONS IN AN ENDEMIC AREA
}

\author{
Norhayati Binti Moktar, Pakeer Oothuman and Fatmah Mohd Salleh \\ Received February 14, 2000/Accepted July 27, 2000
}

\begin{abstract}
The effect of repeated 4 monthly treatment of single dose of $400 \mathrm{mg}$ albendazole on the prevalence and worm burden of Ascaris, Trichuris and hookworm was studied in an endemic area. Repeated 4 monthly treatment, had significant effect in reducing the worm burden of Ascaris and not the prevalence. As for hookworm infection repeated 4 monthly treatment had significant impact in reducing both prevalence and worm burden in the community. However, repeated 4 monthly treatments had no significant impact in reducing the prevalence and worm burden of Trichuris infection in the community. Trichuris infection should be considered as a continuing infection rather than reinfection because of poor cure rate of albendazole at the onset of the study. Significant and strong predisposition $(\mathrm{p}<0.0001)$ were detected after single and repeated 4 monthly treatment in Ascaris and Trichuris infection but not in hookworm infection. Stratification of data indicated that significant and strong predisposition was also seen in gender. This study concludes that changes in mean egg count per gram (mean EPG) is a sensitive indicator in measuring effect of treatment in an endemic area, and repeated 4 monthly treatments has successfully reduced the worm burden of Ascaris and hookworm infection. Subjects remained predisposed to Ascaris infection over 2 reinfection periods, and for hookworm infection evidence of predisposition was seen only over 1 reinfection period.
\end{abstract}

Key words: Predisposition, Ascaris, Trichuris, hookworm, reinfection

\section{INTRODUCTION}

In highly endemic areas of Ascaris, Trichuris and hookworm infections, reinfection can occur as early as 2 months after treatment (Norhayati et al., 1995). By 4 months almost half and one-tenth of the population treated become reinfected with Ascaris and hookworm respectively (Norhayati et al., 1997), and by 6 months the intensity of infection of Ascaris and Trichuris were similar to pre-treatment levels (Elkins et al., 1988; Albinco et al., 1995). Thus a 4 monthly targeted chemotherapy in highly endemic areas may be necessary in order to have an impact on the prevalence and intensity of infection of Ascaris and hookworm infections (Bundy et al., 1990; Albinco et al., 1995; Norhayati et al., 1997).
Predisposition to reinfection following single-treatment has been reported in hookworm infection (Schad and Anderson, 1985), Ascaris infection (Elkins et al., 1986; Thein-Hlaing et al., 1987; Haswell-Elkins et al., 1987; Forrester et al., 1990) and Trichuris infection (HaswellElkins et al., 1987; Bundy et al., 1987; Bundy and Cooper, 1988; Forrester et al., 1990). Predisposition has also been reported following repeated treatments ( 2 reinfection period) in Ascaris infection (Holland et al., 1989; Hall et al., 1992; Chan et al., 1992) and in Trichuris infection (Chan et al., 1992).

This intervention study was conducted in a highly endemic area of Ascaris, Trichuris and hookworm infections. The objectives of this study were to evaluate the impact of 4 monthly $400 \mathrm{mg}$ albendazole treatment for

Department of Parasitology and Medical Entomology, Faculty of Medicine, Universiti Kebangsaan Malaysia, Jalan Raja Muda Abdul Aziz, 50300, Kuala Lumpur, Malaysia

Address for correspondence: Associate Prof. Dr. Norhayati binti Moktar

Department of Parasitology and Medical Entomology, Faculty of Medicine Universiti Kebangsaan Malaysia, Jalan Raja Muda Abdul Aziz, 50300, Kuala Lumpur,

Fax: (603) 2982640 E-mail: 
12 months on the prevalence and intensity of infection/ worm burden (mean eggs per grasm-EPG) of Ascaris, Trichuris and hookworm infections and to examine the evidence of predisposition over 2 reinfection periods.

\section{Materials AND Methods}

\section{Study Area}

This study was part of a bigger study conducted among residents of 6 Orang Asli (Aborigine) villages in the sub-district of Dengkil, Selangor, Malaysia. It was situated about $50 \mathrm{~km}$ from Kuala Lumpur, the capital of Malaysia. Each village comprised a very small population and most of the residents worked as palm oil estate labourers, rubber tappers, farmers or were engaged doing odd jobs such as fishing and selling forest products. Most of them lived in single-roomed houses made of bamboo and wood. Almost all the houses in the villages had no electricity, no pipe water nor toilet facilities. The residents used well or river water for daily use and defaecated in the open among the bushes. Subjects and Parasitologic Surveys

In all 205 children (95 males and 110 females) aged 1-13 years old were included in this study. Stool samples were collected and those found infected were treated with $400 \mathrm{mg}$ of albendazole periodically at 4 months interval for 1 year. The prevalence and worm burden of Ascaris, Trichuris and hookworm infection at pre-treatment (phase I), at 4 months after single treatment (phase II) and at 12 months after repeated treatments (four monthly intervals-phase III) were determined before each intervention and compared. To measure the efficacy of albendazole, stool samples were collected and examined at 1 month after single treatment. All samples were examined by the Kato-Katz technique and worm burden was measured indirectly as EPG (WHO, 1987). For Ascaris, EPG of 1-9,999, 10,000-49,999 and 50,000 and above is defined as mild, moderate or severe infection respectively. For Trichuris and hookworm EPG of 1-1,999, 2,000-9,999 and 10,000 and above is defined as mild, moderate or severe infection respectively (WHO, 1987).

The efficacy of albendazole in reducing the prevalence and worm burden was measured by cure rate and mean egg count reduction rate respectively. Cure rate is the percentage of cured cases at 1 month after the single treatment. The mean egg count reduction rate is the reduction between the mean EPG at 1 month after treatment and the mean EPG at pre-treatment, expressed as a percentage of the mean EPG at pre-treatment.

\section{Statistical Analysis}

Changes in the prevalence and worm burden was compared by 2 proportional test and by paired $\mathrm{t}$-test after logarithmic transformation of data respectively. Correlation of egg counts were analysed using Kendall's Rank Correlation Test. Data were analysed using EpiInfo (EpiInfo version 6.02, 1994) and SPSS for Windows (SPSS, 1993).

\section{RESULTS}

The overall pre-treatment prevalence of Trichuris, Ascaris, and hookworm infections in 205 children (95 boys and 110 girls) was $91.7 \%, 62.5 \%$ and $28.8 \%$ respectively. Almost two-third were infected with moderate and severe infections of Trichuris, $46.3 \%$ had moderate and severe infections of Ascaris and only $1.5 \%$ had moderate infection of hookworm. The cure rate of Ascaris infection was $97.4 \%$ and the mean egg count reduction rate was $99.9 \%$; the cure rate of hookworm infection was $93.1 \%$ and the mean egg count reduction rate was $96.6 \%$. The cure rate of Trichuris infection was low $(5.5 \%)$, however the mean egg count reduction rate was more evident $(49.1 \%)$.

\section{Prevalence of Ascaris, Trichuris and hookworm infec- tions}

Table 1 shows the prevalence of Ascaris, Trichuris and hookworm infections at phase I, phase II and phase III. The overall prevalence of Ascaris infection at phase II and III decreased by $31.8 \%$ and $7.2 \%$ respectively, compared with phase I. However the difference was not statistically significant. The increase in the prevalence of Trichuris infection at phase II and III compared with phase I by $2.3 \%$ and $5.0 \%$ respectively was not statistically significant. For hookworm infection, the overall prevalence at phase II and III compared to phase I decreased by $63.9 \%$ and $69.8 \%$ respectively and the difference was statistically significant. Although the prevalence of Ascaris and Trichuris infections increased in phase III compared to phase II, the difference was not statistically significant. The decrease in the prevalence of hookworm infection between phase II and III was also not significant.

Intensity of Ascaris, Trichuris and hookworm infections

Table 2 shows the mean geometric EPG of Ascaris, Trichuris and hookworm infections at phase I, phase II and phase III. The mean EPG of Ascaris at phase II and III decreased by $53.3 \%$ and $75.0 \%$ respectively compared with phase I and the difference was statisti- 
Table 1 Prevalence of Ascaris, Trichuris and hookworm infection at phase I, II and III

\begin{tabular}{lccccc}
\hline Infections & \multicolumn{3}{c}{ Prevalence $(\%)$} & \multicolumn{2}{c}{ Percent reduction } \\
\hline Phase & I & II & III & I-II / I & I-III / I \\
\hline Ascaris & 62.5 & 42.6 & 58.0 & $-31.8(\mathrm{p}>0.05)$ & $-7.2(\mathrm{p}>0.05)$ \\
\hline Trichuris & 91.7 & 93.8 & 96.3 & $+2.3(\mathrm{p}>0.05)$ & $+5.0(\mathrm{p}>0.05)$ \\
\hline Hookworm & 28.8 & 10.4 & 8.7 & $-63.9(\mathrm{p}<0.05)$ & $-69.8(\mathrm{p}<0.05)$ \\
\hline
\end{tabular}

Table 2 Mean intensity of Ascaris, Trichuris and hookworm infection at phase I, II and III

\begin{tabular}{lrrrrc}
\hline Infections & \multicolumn{2}{c}{ Mean EPG $($ Geometric $)$} & \multicolumn{2}{c}{ Percent reduction } \\
\hline Phase & \multicolumn{1}{c}{ I } & \multicolumn{1}{c}{ II } & III & I-II / I & I- III / I \\
\hline Ascaris & 24,071 & 11,251 & 6,008 & $-53.3(\mathrm{p}<0.05)$ & $-75.0(\mathrm{p}<0.05)$ \\
\hline Trichuris & 5,516 & 5,604 & 5,822 & $+1.6(\mathrm{p}>0.05)$ & $+5.5(\mathrm{p}>0.05)$ \\
\hline Hookworm & 131 & 59 & 10 & $-55.0(\mathrm{p}<0.05)$ & $-92.4(\mathrm{p}<0.05)$ \\
\hline
\end{tabular}

cally significant. For Trichuris, the increase in the mean EPG at phase II and III compared with phase I by $1.6 \%$ and $5.5 \%$ respectively was not statistically significant. For hookworm infection, there was a significant decrease of mean EPG at phase II and III compared to phase I. Although the mean EPG of Trichuris infection increased in phase III compared to phase II, the difference was not statistically significant. The decrease in the mean EPG of Ascaris and hookworm infections between phase II and III was statistically significant.

\section{Correlation of egg counts}

The correlation for overall and stratified EPG of Ascaris, Trichuris and hookworm infections according to gender at phase I, II and III are shown in Table 3. Analysis shows that in Ascaris infection, there is a strong and significant positive correlation of mean EPG between phase I and II and phase I and III. When the data was stratified according to gender, the level of significance remained strong and significant except in males between phase I and III.

In Trichuris infection, strong and significant overall correlation was detected in all phases and when the data was stratified according to gender. In hookworm infection significant correlation was detected between phase I and II and between phase II and III but with lower significant level. When the data was stratified according to gender, significant correlation was detected in males (phase I \& II and phase I \& III) and in females (phase I \& II), although the level was lower.

\section{DISCUSSION}

In endemic areas of Ascaris, Trichuris and hookworm infections, where reinfections occur continuously, repeated treatments with effective antihelminthic were required to reduce worm burden (measured by mean EPG) in the community. The interval required varied. A study done in Burma suggests that 3 monthly repeated treatments give significant impact on the prevalence and worm burden of Ascaris (Thein-Hlaing et al., 1987). In contrast, a study in Malaysia reports that 6 monthly repeated treatment has significant effect in reducing both prevalence and worm burden of Ascaris and Trichuris (Chan et al., 1992). On the other hand, other studies show that by 6 months to 1 year, the prevalence and worm burden of Ascaris and Trichuris have reached

Table 3 Correlation of Ascaris, Trichuris and hookworm mean EPG between phase I and II and phase I and III

\begin{tabular}{ccc}
\hline Group & Phase I and II & Phase I and III \\
\hline Ascaris & & \\
\hline Overall & $0.3517 \ddagger$ & $0.2902 \ddagger$ \\
\hline Gender & \\
\hline Male & $0.3531 \ddagger$ & $0.2457 \dagger$ \\
Female & $0.3522 \ddagger$ & $0.3480 \ddagger$ \\
\hline Trichuris & & $0.4474 \ddagger$ \\
\hline Overall & $0.5388 \ddagger$ & $0.4198 \ddagger$ \\
\hline Gender & & $0.4758 \ddagger$ \\
Male & $0.5533 \ddagger$ & \\
Female & $0.5327 \ddagger$ & 0.1377 \\
\hline Hookworm & & \\
\hline Overall & $0.3304 \dagger$ & 0.1173 \\
\hline Gender & & -0.0564 \\
\hline Male & $0.2730 *$ & \\
Female & $0.4007 \ddagger$ &
\end{tabular}

$*$ Significant correlation at $\mathrm{p}<0.05$

$\dagger$ Significant correlation at $\mathrm{p}<0.01$

$\ddagger$ Significant correlation at $\mathrm{p}<0.0001$ 
the pre-treatment level (Holland et al., 1989; Elkins et al., 1988; Albonico et al., 1995).

We studied the impact of 4 monthly treatment (for 12 months) on the prevalence and worm burden of Ascaris, Trichuris and hookworm infections in an endemic area. The results of our study showed that repeated 4 monthly treatments had no significant impact in reducing prevalence and worm burden of Trichuris infection in the community and this was different from an earlier study done in Malaysia (Chan et al., 1992). Poor cure rate of single dose of $400 \mathrm{mg}$ albendazole against Trichuris infection and high prevalence of moderate and severe infections of the worm in this community compared to the study done by Chan et al. (1992) were the main reasons for the failure of repeated 4 monthly treatments in reducing prevalence and worm burden of Trichuris infection. In the present study, Trichuris infection should be considered as a continuing infection rather than reinfection because of poor cure rate at the onset. This factor explains the increases in prevalence and worm burden of Trichuris infection in this study.

Repeated 4 monthly treatments had significant effect in reducing worm burden of Ascaris but not the prevalence. The increase in Ascaris prevalence after repeated 4 monthly treatments can be explained by the continuing infection in the community. This factor suggests that the use of antihelminth can only control this infection by significantly reducing the worm burden in the community and not prevent people from becoming infected. As for hookworm infection, repeated 4 monthly treatments had significant impact in reducing both prevalence and worm burden in the community. Low prevalence, low worm burden and a drastic reduction in worm burden in the community following treatment may explain these findings. Besides that, the speed with which the worm burden bounces back to its pre-treatment level differs between species for example it is slower in hookworm and faster in Trichuris and Ascaris (Anderson, 1986). This finding also indicates that the mean egg count is a sensitive indicator in evaluating the progress of periodic chemotherapy in the control of Ascaris and hookworm infections. A similar finding was reported by Anderson and May (1985).

Based on this study, it is more relevant to suggest implementation of repeated 4 monthly treatments in the planning of periodic chemotherapy schedule in an endemic area. Such a suggestion is also supported by our earlier study in the same community, where after 4 months of treatment, the reinfection rate of Ascaris and hookworm was seen in $50.0 \%$ and $10.0 \%$ of the subjects respectively (Norhayati et al., 1997). Only one-fifth of the subjects infected with Ascaris reached their pretreatment intensity (Norhayati et al., 1997). Our presest study also suggests that the mean EPG should be used as an indicator to monitor the progress of periodic chemotherapy in the community.

This study examines the evidence of predisposition over one and two reinfection periods of Ascaris, Trichuris and hookworm infections. For Trichuris infection evidence of predisposition was seen over one and two reinfections. This evidence was seen as a result of poor cure rate at the start.

As for Ascaris infection, evidence of predisposition was seen after one and two reinfection periods. This finding generally agreed with most of the studies done before (Holland et al., 1989; Hall et al., 1992; Chan et al., 1992). For hookworm infection evidence of predisposition after one reinfection period was weak and after two reinfection periods, the evidence was negative. Predisposition following one reinfection period has been reported in hookworm infection by Schad and Anderson (1985). These findings indicate that subjects remained predisposed to Ascaris infection over 2 reinfection periods and for hookworm infection evidence of predisposition was only seen over 1 reinfection period.

It can be concluded that repeated 4 monthly treatments have successfully reduced the worm burden of Ascaris and hookworm infection in the Orang Asli community. The risk of acquiring similar worm burden as before treatment was only evident in Ascaris and not in hookworm infection.

\section{REFERENCES}

1) Albonico, M., Smith, P.G., Ercole, E., Hall, A., Chwaya, H.M., Alawi, K.S. and Savioli, L. (1995): Rate of reinfection with intestinal nematodes after treatment of children with mebendazole or albendazole in a highly endemic areas. Trans. R. Soc. Trop. Med. Hyg., 89, 538541

2 ) Anderson, R.M. and May, R.M. (1985): Helminth infections of humans: mathematical models, population dynamics and control. Advances in Parasitology, 24, 1101

3 ) Anderson, R.M. (1986): The population dynamics and epidemiology of intestinal nematode infections. Trans. R. Soc. Trop. Med. Hyg., 80, 686-696

4 ) Bundy, D.A.P., Cooper, E.S., Thompson, D.E., Didier, J. M., Anderson, R.M. and Simmons, I. (1987): Predisposition to Trichuris trichiura infection in humans. Epid. Infec., 98, 65-71 
5 ) Bundy, D.A.P. and Cooper, E.S. (1988): The evidence of predisposition to trichuriasis in Caribbean communities. Trans. R. Soc. Trop. Med. Hyg., 82, 251-256

6 ) Bundy, D.A.P., Wong, W.S., Lewis, L.L. and Horton, L. (1990): Control of geohelminths by delivery of targeted chemotherapy through schools. Trans. R. Soc. Trop. Med. Hyg., 84, 115-120

7 ) Chan, L., Kan, S.P. and Bundy, D.A.P. (1992): The effect of repeated chemotherapy on the prevalence and intensity infection of Ascaris lumbricoides and Trichuris trichiura. Parasitol., 104, 371-377

8 ) Elkins, D.B., Haswell-Elkins, M.R. and Anderson, R.M. (1986): The epidemiology and control of intestinal helminths in the Pulikat Lake region of Southern India 1. Study design and pre- and post-treatment observation on Ascaris lumbricoides infection. Trans. R. Soc. Trop. Med. Hyg., 80, 774-792

9 ) Elkins, D.B., Haswell-Elkins, M.R. and Anderson, R.M. (1988): The importance of host age and sex to patterns of reinfection with Ascaris lumbricoides following mass anthelminthic treatment in a South Indian fishing community. Parasitol., 96, 171-184

10) Epilnfo version 6.02. A word processing Data base \& Statistics Program for Public Health. Produced by The Division of Surveillance and Epidemiology, Epidemiology Program off Centres for Diseases Control \& Preventive and World Health Organization. 1994.

11) Forrester, J.E., Scott, M.E., Bundy, D.A.P. and Golden, M.H.N. (1990): Predisposition of individual and families in Mexico to heavy infection with Ascaris lumbricoides and Trichuris trichiura. Trans. R. Soc. Trop. Med. Hyg., 84, 272-276

12) Hall, A., Anwer, K.S. and Tomkins, A.M. (1992): Intensity of reinfection with Ascaris lumbricoides and its implication for parasite control. Lancet, 339, 1253-1257

13) Haswell-Elkins, M.R., Elkins, D. and Anderson, R.M. (1987): Evidence of predisposition in humans to infection with Ascaris, hookworm, Enterobius and Trichuris in a South Indian fishing community. Parasitol., 95, 339-354

14) Holland, C.V., Asaolu, S.O., Crompton, D.W.T., Stoddart, R.C., MacDonald, R. and Torimiro, S.E.A. (1989): The epidemiology of Ascaris lumbricoides and other soil-transmitted helminths in primary school children from Ife-Ife, Nigeria. Parasitol., 99, 275-285

15) Norhayati, M., Oothuman, P., Fatmah, M.S., Muzain, M. Y. and Zainuddin, B. (1995): Hookworm infection and reinfection following treatment among Orang Asli children. Med. J. Malaysia, 50, 314-319

16) Norhayati, M., Oothuman, P., Azizi, O. and Fatmah, M. S. (1997): Efficacy and effect of single dose albendazole on the prevalence and intensity infection of soil-transmitted helminths in Orang Asli (Aborigines) children in Malaysia. Southeast Asian J. Trop. Med. Pub. Hlth., 28, 161-168

17) Schad, G.A. and Anderson, R.M. (1985): Predisposition of hookworm infection in humans. Science, 228, 15371540

18) Statistical Package for Social Sciences, for Windows (Release 6.0). 1993. SPSS Inc. Chicago, Illinois.

19) Thein-Hlaing, Than-Saw and Myint-Lwin (1987): Reinfection of people with Ascaris lumbricoides following single, 6 months and 12 months interval mass chemotherapy in Opko village, rural Burma. Trans. R. Soc. Trop. Med. Hyg., 81, 140-146

20) WHO (1987): Prevention and control of intestinal parasitic infections. Tech. Rep. Ser. World Health Organ., 749 